\title{
The Influence of Technical Similarity Relation on Innovation Performance, the Cooperative Relation as Mediator
}

\author{
ZHANG Xiaoli \\ School of Business Information, \\ Shanghai University of International Business and Economics, \\ Shanghai 201600, China \\ zhangxiaoli@suibe.edu.cn
}

\begin{abstract}
The technical similarity network and the cooperative network were built. The technical similarity relation on different thresholds may reflect a certain degree of technology competition situation. So the influence of technical similarity relation on the innovation performance is studied. When technical similarity value between 0.3 and 0.5 , technical similarity relation has negative effects on the innovation performance, and the cooperative relation is a part or complete mediator.
\end{abstract}

Keywords: Technical Similarity Relation; Innovation Performance; Cooperative Relation; Mediating Effect

\section{Introduction}

If enterprise wants to be the leader of technological innovation in the industry, it has to know the technical development situation timely and accurately, apperceive the pressure of technology competition, explore the potential of technology opportunities and grasp the time to cooperation. Patents applied by enterprises in a period of time within the industry, carrier of enterprise technology innovation, can reflect a certain degree of hot technology and technology development of the industry. Activities taken by enterprises in a period of time within the industry, such as the joint venture, technology investment and technology M\&A can reflect technical cooperation among enterprises in a certain degree based on funds. But how to research on the development of industrial technology and find the pressure of technology competition by patents? Does the applying for patents have relation to cooperative activities? Researches on knowledge overlapping provide us a method to measure the degree of technology competition. Knowledge overlapping is the same or similar technology among enterprises. It means similarity of enterprises' knowledge base. It also reflects the differences among enterprises' knowledge base (Yang $\&$ Pan, 2009). Technical similarity or difference between cooperative enterprises has impacts on innovation performance.

Researches on knowledge management think that similar knowledge is easy to digest and absorb, so technology similarity is good to knowledge integration in the process of cooperation. The knowledge has attributes of specificity and viscosity, and cannot be transferred through enterprises easily. Technique could be more confluent in knowledge combination when technology similar degree of knowledge base is higher. If enterprises' knowledge bases are too different, their technological developing paths are far away. It is difficult to understand and absorb each other's knowledge to form sustainable development planning of common. And that is bad to cooperative R\&D and innovation in the future. (Xiang \& Cai, 2010). Enterprise has stronger absorbing ability for similar knowledge. New knowledge similar to the existing technology is easier to digest, absorb, and cost less effort and money to integrate, so the consistency of new knowledge and original knowledge base is positively influence the technology innovation performance 
(Liu \& Cai, 2011). But researches on competition and social network capital theory think that the unique knowledge base is rare and difficult to imitate, so different technology makes enterprise irreplaceable and more valuable in the process of cooperation. Enterprise with different types of technique and knowledge base is at the core position in the enterprise network. The technical differences make the enterprise has the unique knowledge base out of the ordinary. Different Knowledge base helps to discover the valuable complementary knowledge, that can enhance the joint effect of innovation and produce new knowledge (Ahuja \& katila, 2001), prevent the core technology of stiffness. Enterprises in the same market or providing similar products or services might compete with each other (Hou, Yang \& Yao, 2010). Although similarity or difference of knowledge base has effects on technological innovation, there is no research on discussing how the influence of technical similarity relations on innovation performance. Relations of technical similarities beyond the threshold can reflect technology competition to a certain extent. Then how to define the threshold is the key problem.

Researches on social network theory think that the cooperative network is the channel to access funds, share information and transfer knowledge, so it is another important resource for enterprises to improve the performance of technology innovation. Enterprise with high centrality in the cooperative network is at the core location which is good to search and exchange information (Qian, Yang \& Xu, 2010). Enterprise with more structural holes in the cooperative network has more advantages on structure, could obtain and compare variously non-repetitive information and so get the real valuable knowledge through noises. So sparse and non-closed network with some structural holes is the ideal network structure and the key to promote the innovation performance (Lechner, Frankenberger \& Floyd, 2010). In a changing environment, enterprise with high degree of betweenness has high performance, and enterprise with high centrality does not have high performance. With the aggravation of environmental changing, cooperative network can no longer provide the necessary information to the fast and effective strategic, so betweenness and centrality have negative effect on enterprise performance (Koka \& Prescott, 2008). Although the cooperative network has effects on technological innovation, there is no research on discussing the timing to choose cooperation.

The paper builds the knowledge base network by patent data and cooperative network by equity transaction data. The technical similarity relationship could be found by the similarity threshold is set on knowledge overlapping network. Who is facing the most similar object, and who is the broker of different technical fields in the industries could be found, when centrality and betweenness of technical similarity network are analyzed. The influence of technical similarity relationship on the innovation performance is studied, and the cooperative relationship is mediator. The causal chain of technical similarity relations, direct ties in cooperation and the technology innovation is built. Defining the technical similarity threshold level can analyze the technology competition in the industry. Therefore, the enterprise can choose the effective and appropriate cooperative time. 


\section{Network Modeling}

\subsection{Technical Similarity Network}

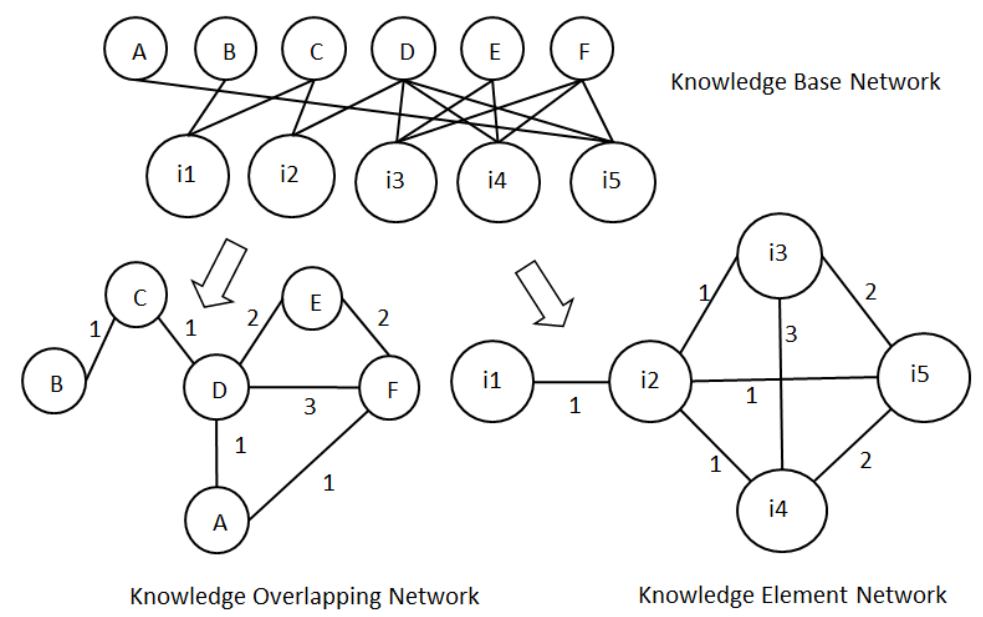

Figure 1. Knowledge Base Network

The upper part of Figure 1 is the knowledge base network which is used to describe the relationship of enterprises owning patents. Nodes could be divided into two classifications. One classification is enterprise node, such as A,B,C,... The other classification is knowledge element node (the IPC code), such as $11, \mathrm{i} 2, \mathrm{i} 3, \ldots$. If the enterprise has an IPC category of patents, a link would be drawn between the enterprise and the IPC class, such as the edge between A and i5. So a knowledge base network could be drawn.

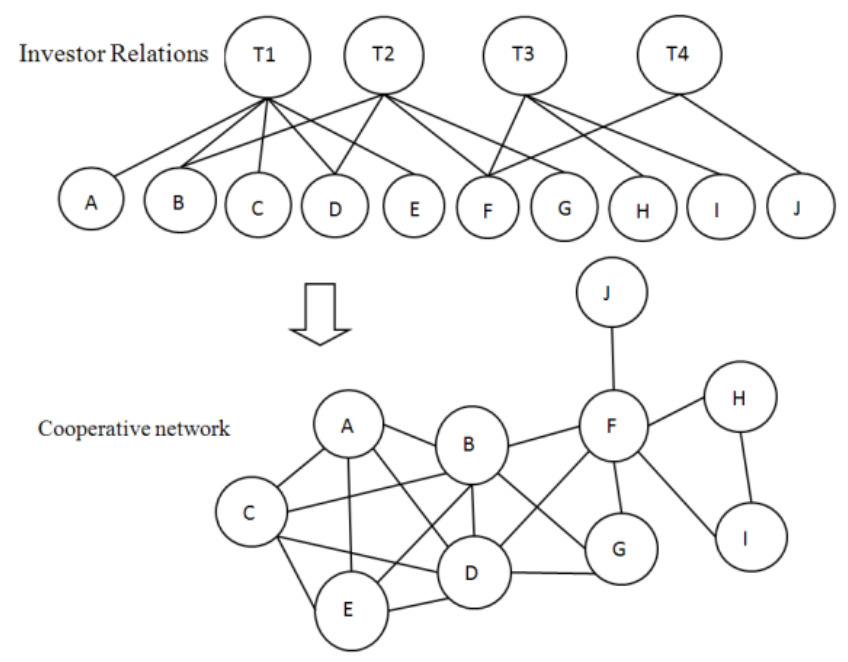

Figure 2. Cooperative Network

In the lower left part of Figure 1, the knowledge base network is projected to the enterprise node to form the enterprise knowledge overlapping network. Nodes in the knowledge overlapping network are enterprises. The weight value of edge means the number of overlapping IPC categories between two enterprises. The weight value 3 on the edge between $\mathrm{D}$ and $\mathrm{F}$ means that enterprise $\mathrm{D}$ and $\mathrm{F}$ have three same IPC categories which are i3, i4 and i5. That means there is certain degree of technology competition between them because their knowledge bases are so similar that could be superseded by each other. On the other hand, there are also opportunities for cooperation between them because their knowledge bases are so similar that is easy to fuse. 
The enterprise knowledge overlapping network is dichotomized as following to form the technical similarity network. Two enterprises' technical similarity degree is calculated according to the method of Sampson (2007) when the edge value is more than 1 in the knowledge overlapping network. The formula is $\frac{\mathrm{f}_{\mathrm{i}} \mathrm{f}_{\mathrm{j}}^{\prime}}{\left[\left(\mathrm{f}_{\mathrm{i}} \mathrm{f}_{\mathrm{i}}^{\prime}\right)\left(\mathrm{f}_{\mathrm{j}} \mathrm{f}_{\mathrm{j}}^{\prime}\right)\right]^{\frac{1}{2}}} \cdot \mathrm{f}_{\mathrm{i}}=\left[\mathrm{r}_{\mathrm{i} 1}, \mathrm{r}_{\mathrm{i} 2}, \ldots, \mathrm{r}_{\mathrm{in}}\right]$, $r_{i k}=\frac{N_{i k}}{N_{i}}, \quad k=1, \ldots n 。 N_{i k}$ means patents of enterprise $i$ on the $k$ classification. $N_{i}$ means all patents of enterprise $\mathrm{i}$. The technical similarity thresholds are set as $(0.1,0.3,0.5,0.7$ 0.9). If the technical similarity between two enterprises is more than threshold, the edge value is set to 1 in the technical similarity network, or it is set to 0 . So a series of technical similarity network are formed according to different threshold level.

\subsection{Cooperative Network}

Cooperative network is relationship formed by the joint venture, joint investment, cross shareholdings and part of the acquisition. If two enterprises have cross shareholdings and part of the acquisition, one link can be drawn between them directly. If some enterprises have the joint venture or joint investment, links can be made according to Figure 2. The upper part of Figure 2 is the tree structure relation of the joint venture or joint investment. The targets (T1, T2 and T3) are built by enterprises A to J through joint venture or joint investment. The lower half of the Figure 2 is their cooperative network. Enterprise A, B, C, D and E build the target T1, so they have direct ties to each other. Enterprise B, D, F and $\mathrm{G}$ build the target T2, so they have direct ties to each other. So, enterprise A has direct tie with enterprise $\mathrm{B}$, but indirect tie with enterprise $\mathrm{F}$.

\section{Technical Similarity Relation, Cooperative Relation and Innovation Performance}

Knowledge is special, viscosity and hard to flow among enterprises (Xiang \& Cai, 2011). Especially, valuable and complementary knowledge is hard to find when technical similarity is too high (Yang \& Pan, 2009). Technology path will become narrow. That will limit the R\&D and business development opportunities (Miller, 2006). It is also hard for an enterprise to get valuable and complementary knowledge in the industry when it faces so many objects with high technical similarity. According to the resource base theory, knowledge resources, which are rare and difficult to imitate, can bring to the enterprise competitive advantage. When enterprise knowledge base has high technical similarity with so many other enterprises', the knowledge base is ordinary and invaluable resource. It cannot bring to the enterprise competitive advantage in innovation. The enterprise has to face so many rivals with similar technical ability. And it is hard to innovate. So hypothesis 1 is put forward, technical similarity relation has negative effects on innovation performance.

Technology resource, especially the core technology, is the strategic resource that cannot be transferred through market mechanism (Larsson \& Bengtsson, 1998). Knowledge is hard to be absorbed because science and technology are complex, the market and the external environment are uncertainty, the ability of enterprise is deficient and naïve (Zollo, Reuer \& Singh, 2002). The enterprise may prefer to use joint venture, joint investment, cross shareholding and $\mathrm{M} \& \mathrm{~A}$ way to get knowledge resources which are difficult to be transferred and absorbed (Bresman, Birkinshaw \& Nobel, 1999). Big multi-technology firm takes acquisition of small technical enterprises to get their core technology. Small enterprises want to construct ecological coexistence relationship with big firms that have rich resources at the key period of the development (Granstrand \& Sjolander, 1990). Cooperation can make both sides achieve economies of scale and scope in the capital and technology. So cooperator can pay more attention to basic research. It is good to development and application for advanced technology. Knowledge sharing and 
communication can broaden the technology view of enterprises. A more comprehensive knowledge is conducive to integrate both specific advantages, develop new technology and new products, and reduce the risk of independent research and development. So hypothesis 2 is put forward, cooperative relation has positive effects on innovation performance.

Enterprises are inclined to use direct cooperation for technological innovation when they have overlapping technology structure (Xiang\& Cai, 2010). Overlapping knowledge base can search, identify and transfer valuable technology by cooperative network, that is helpful to increase mutual trust in the complex environment, improve the communication mechanism and cooperation between the two sides, understand and absorb each other's knowledge, form the sustainable development planning of common, and enhance the efficiency of cooperation (Hu \& Pan, 2006). The technology difference among members of the alliance is at middle level, the contribution of technology alliance to the technological innovation performance is max (Sampson, 2007). In the industry, when enterprise faces so many objects with high technical similarity, it is easily to search and find out the target for cooperation. Knowledge overlapping can weaken the asymmetry of information between each other, enhance mutual understanding and trust through cooperation. So hypothesis 3 is put forward, technical similarity relation has positive effects on cooperative relation.

\section{Data, Model and Variable}

Enterprises are taken from the global $\mathrm{R} \& \mathrm{D}$ top list released by British business, innovation and skills (BIS). Enterprises of the network and communication technology, hardware and equipment more than 4 times on the list from 2002 to 2009 are selected as the samples, which have not been thoroughly acquisition after 2009. There are totally 88 enterprises, which are named communication and technical equipment manufacturing enterprises. R\&D funds (in millions) and the number of employees are from the list. Patent data of samples from 2002 to 2008 are downloaded from WIPO website. They are used to build a series of knowledge base network of time window in 3 years according to the upper part of Figure 1, such as knowledge base networks in five periods 2002-2004, 2003-2005, 2004-2006, 2005-2007 and 2006-2008. Technical similarity networks at different thresholds in different stages are built according to section 2.1. Then the node degree could be calculated to measure technical similarity relations. Equity transaction data of samples from 2003 to 2009 are downloaded from the Zephyr global M\&A transaction database. They are used to build a series of cooperative network of time window in 3 years according to Figure 2, such as cooperative networks in five periods 2003-2005, 2004-2006, 2005-2007, 2006-2008 and 2007-2009. Then the node degree could be calculated to measure direct ties.

$$
\begin{gathered}
\mathrm{Y}=\mathrm{cX}+\mathrm{e}_{1} ; \\
\mathrm{M}=\mathrm{aX}+\mathrm{e}_{2} ; \\
\mathrm{Y}=\mathrm{c}^{\prime} \mathrm{X}+\mathrm{bM}+\mathrm{e}_{3}
\end{gathered}
$$

Formula 1 on the right is used to test the effect of similarity relations on the innovation performance, and the direct ties as mediator. Independent variable $\mathrm{X}$ is node degree (technical similarity relations) of the technical similarity network. Mediator variable $\mathrm{M}$ is node degree square (direct ties) of the cooperative network. Dependent variable $\mathrm{Y}$ is counts of patents of the year 2005, 2006, 2007, 2008 and 2009. Formula 1 describes that the independent variable $\mathrm{X}$ has influence on the dependent variable $\mathrm{Y}$ through mediator variable M. $\mathrm{c}$ is the total effects of $\mathrm{X}$ on $\mathrm{Y}$, $\mathrm{c}^{\prime}$ is the direct effects of $\mathrm{X}$ on $\mathrm{Y}$, and $\mathrm{a} \times \mathrm{b}$ is the mediating effect of $\mathrm{X}$ on $\mathrm{Y}$ through $\mathrm{M}$. Controlling variables are knowledge base width (IPC classifications), depth (counts of patents). They are in five periods 2002-2004, 2003-2005, 2004-2006, 2005-2007 and 2006-2008. Indirect ties (in five periods 20032005, 2004-2006, 2005-2007, 2006-2008 and 2007-2009), R\&D strength (logarithmic 
R\&D funds) and enterprise size (logarithmic employee number). They are in the year 2005, 2006, 2007, 2008 and 2009). All Independent, mediator and dependent variables are standardized. The dependent variable is non negative count ultra-discrete data. The difference of its mean and standard deviation is very large. Hausman (1984) suggests using the negative binomial regression model. So the negative binomial regression models of fixed effect are used to analysis the influence of technical similarity relation on innovation performance, and the cooperative relation as mediator. Test method for intermediary variable (Baron \& Kenny, 1986): Firstly, c is significant; Secondly, a is significant; Thirdly, when $\mathrm{X}$ is controlled, $\mathrm{b}$ is significant. When a or b is not significant, the mediating effect is judged by method of Wen (2004) or Zhang(2011). When c is not significant, the mediating effect is judged by method of Zhao (2010).

\section{Results and Analysis}

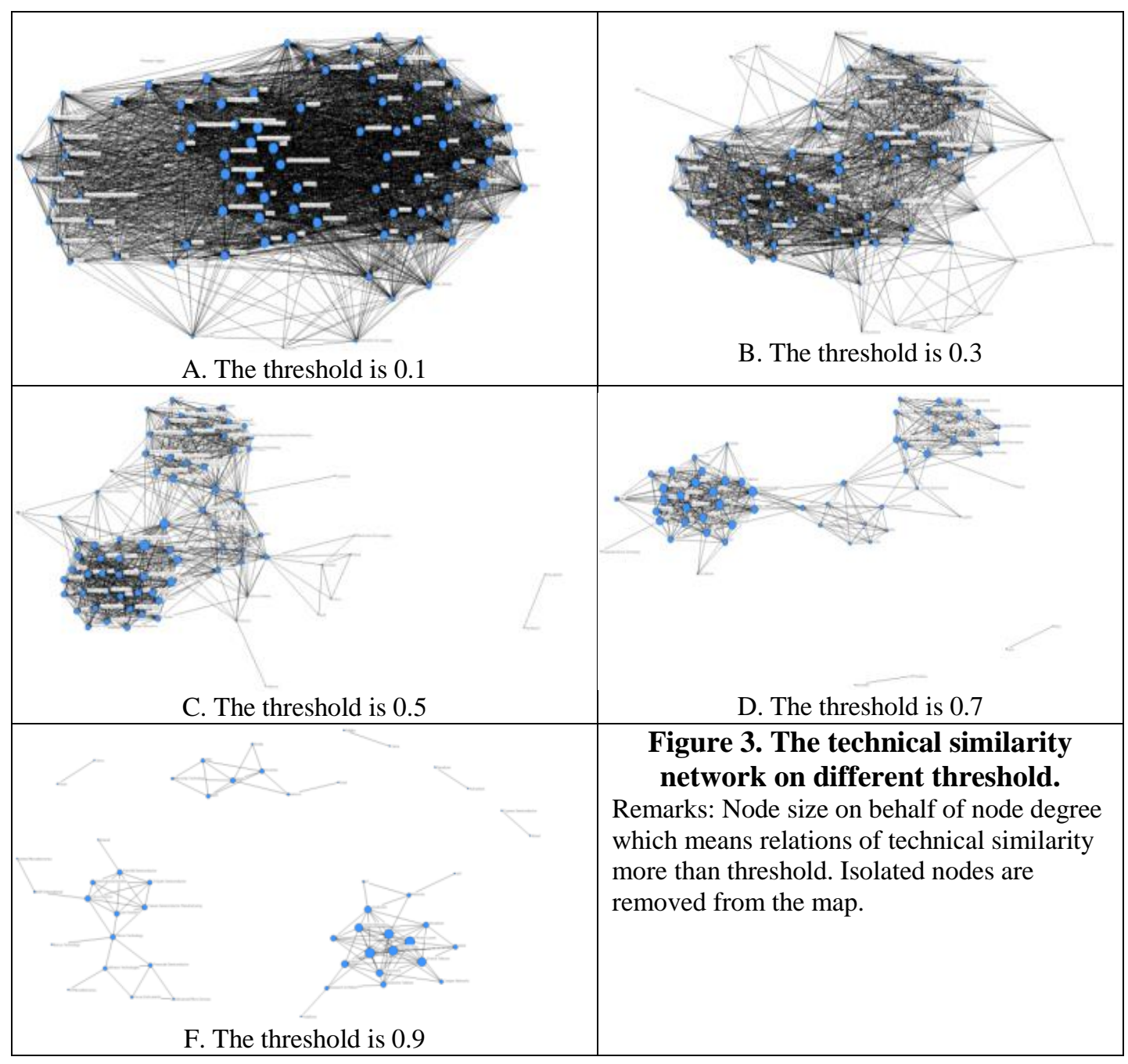

Figure 3 are the technical similarity networks on threshold $0.1,0.3,0.5,0.7$ and 0.9 in the period 2006-2008. Nodes in the networks are enterprises. Edges between two enterprises mean that their knowledge bases are similar above the threshold. When the threshold is 0.1 , the technical similarity network is so dense that it cannot reflect the technical similarity relations clearly. When the threshold is more than 0.3 but less than 0.7, the technical similarity network retains the most nodes and the important links, and 4 clusters could be found. Knowledge bases of enterprises in the same cluster have high technical similarity. Knowledge bases of enterprises in the different cluster have low technical similarity, but high technical complement. The key nodes among clusters are 
like bridges to join different knowledge base to form a technical link. It is important to realize joint innovation beyond technical similar $R \& D$ develop. When the threshold is 0.9 , the technical similarity network is not to be a whole structure, but to be several separating clusters of clear boundary. Edges of value less than 0.9 are disappearing, and many nodes turn to be isolated. The technical similarity relations among clusters are neglected very seriously. The technical similarity network cannot be used to reflect the technical similarity relations in the industry.

Table 1 is the correlations among variables. The innovation performance has the weakest correlation with the technical similarity relation at threshold 0.1 , and the strongest correlation with the technical similarity relation at threshold 0.7. The direct and indirect ties have the weakest correlation with the technical similarity relation at threshold 0.1 , and the strongest correlation with the technical similarity relation at threshold 0.5.

Table 1. Correlations

\begin{tabular}{|c|c|c|c|c|c|c|c|c|c|c|c|}
\hline & 1 & 2 & 3 & 4 & 5 & 6 & 7 & 8 & 9 & 10 & $\begin{array}{l}1 \\
1\end{array}$ \\
\hline $\begin{array}{l}\text { 1Innovation } \\
\text { performance }\end{array}$ & 1 & & & & & & & & & & \\
\hline $\begin{array}{l}\text { 2Knowledge } \\
\text { Width }\end{array}$ & $0.479^{*}$ & 1 & & & & & & & & & \\
\hline $\begin{array}{l}\text { 3Knowledge } \\
\text { Depth }\end{array}$ & $0.928^{*}$ & $0.500^{*}$ & 1 & & & & & & & & \\
\hline $\begin{array}{l}\text { 4Similarity } \\
\text { Relation }(>0.1 \\
\text { ) }\end{array}$ & $0.169^{*}$ & $0.339^{*}$ & ${ }_{*}^{0.201^{*}}$ & 1 & & & & & & & \\
\hline $\begin{array}{l}\text { 5Similarity } \\
\text { Relation }(>0.3\end{array}$ & $0.222^{*}$ & $0.264^{*}$ & $0.248^{*}$ & $0.790^{*}$ & 1 & & & & & & \\
\hline $\begin{array}{l}\text { 6Similarity } \\
\text { Relation }(>0.5 \\
\text { ) }\end{array}$ & $0.278^{*}$ & $0.232^{*}$ & $0.319^{*}$ & $0.578^{*}$ & $0.869^{*}$ & 1 & & & & & \\
\hline $\begin{array}{l}\text { 7Similarity } \\
\text { Relation(>0.7 } \\
\text { ) }\end{array}$ & $0.289^{*}$ & $0.239^{*}$ & $0.352^{*}$ & $0.334^{*}$ & $0.581^{*}$ & $0.820^{*}$ & 1 & & & & \\
\hline 8 Direct Ties & $0.424^{*}$ & $0.209^{*}$ & $0.479^{*}$ & $0.163^{*}$ & $0.251^{*}$ & $0.310^{*}$ & $0.283^{*}$ & 1 & & & \\
\hline $\begin{array}{ll}9 & \text { Indirect } \\
\text { Ties } & \\
\end{array}$ & $\begin{array}{l}0.270^{*} \\
*\end{array}$ & $0.195^{*}$ & $\begin{array}{l}0.247^{*} \\
*\end{array}$ & $0.153^{*}$ & $0.194^{*}$ & $0.227^{*}$ & $0.202^{*}$ & $0.390^{*}$ & 1 & & \\
\hline $\begin{array}{l}\text { 10R\&D } \\
\text { Strength }\end{array}$ & $0.556^{*}$ & $0.487^{*}$ & $0.581^{*}$ & $0.255^{*}$ & $0.277^{*}$ & $0.310^{*}$ & $0.317^{*}$ & $0.559^{*}$ & $0.351^{*}$ & 1 & \\
\hline $\begin{array}{l}11 \text { company } \\
\text { size }\end{array}$ & $0.362^{*}$ & $0.369^{*}$ & $0.356^{*}$ & $0.137^{*}$ & $0.182^{*}$ & $0.263^{*}$ & $0.314^{*}$ & $0.434^{*}$ & $0.341^{*}$ & $0.674^{*}$ & 1 \\
\hline
\end{tabular}

Table 2 are negative binomial regression models of fixed effects used to analysis the influence of technical similarity relation on innovation performance, and the cooperative relation as mediator. Model 7 is the influence of mediator variable on the dependent variable. Model 1 to 3 is based on technical similarity value more than 0.3 . Model 1 , technical similarity relation has negative effects on innovation performance, and hypothesis 1 is established. Model 2, technical similarity relation has positive effects on cooperative relation, and hypothesis 3 is established. Model 7, cooperative relation has positive effects on innovation performance. Model 3 means that when technical similarity relation is controlled, cooperative relation still has positive effects on innovation performance, and Hypothesis 2 is established. Model 4 to 6 is based on technical similarity value more than 0.5 . Model 4 , the negative effect of technical similarity relation on innovation performance is not significant, and Hypothesis 1 is not established. Model 5, technical similarity relation has positive effects on cooperative relation, and Hypothesis 3 is established. Model 6 means that when technical similarity relation is controlled, cooperative relation still has positive effects on innovation performance, and hypothesis 2 is established. 
Models which are based on technical similarity value more than 0.1 or 0.7 are tested but not showed because of the length of the paper. They all failed to prove that technical similarity relations have significant effects on innovation performance. And also they all failed to prove that technical similarity relations have significant effects on cooperative relation. They only proved that when technical similarity relation is controlled, cooperative relation still has positive effects on innovation performance. So, according to the method of Zhao (2010), when technical similarity value is more than 0.1 or 0.7 , the technical similarity relations have no significant negative influence on the innovation performance, and the cooperative relation is not mediator.

Table 2. The Negative Binomial Regression Models of fixed effects

\begin{tabular}{|l|l|l|l|l|l|l|l|}
\hline & \multicolumn{1}{|c|}{$\begin{array}{c}\text { Model 1 } \\
(\mathbf{X} \rightarrow \mathbf{Y})\end{array}$} & $\begin{array}{c}\text { Model 2 } \\
(\mathbf{X} \rightarrow \mathbf{M})\end{array}$ & $\begin{array}{c}\text { Model 3 } \\
(\mathbf{X}, \mathbf{M} \rightarrow \mathbf{Y}\end{array}$ & $\begin{array}{c}\text { Model 4 } \\
(\mathbf{X} \rightarrow \mathbf{Y})\end{array}$ & $\begin{array}{c}\text { Model 5 } \\
(\mathbf{X} \rightarrow \mathbf{M})\end{array}$ & $\begin{array}{c}\text { Model 6 } \\
(\mathbf{X}, \mathbf{M} \rightarrow \mathbf{Y} \\
)\end{array}$ & $\begin{array}{c}\text { Model 7 } \\
(\mathbf{M} \rightarrow \mathbf{Y}\end{array}$ \\
\hline $\begin{array}{l}\text { Log } \\
\text { Likelihood }\end{array}$ & -1667.702 & -998.605 & -1665.181 & -1670.030 & -998.732 & -1667.443 & -1668.440 \\
\hline Wald chi2 & $181.18^{* * *}$ & $165.22^{* * *}$ & $200.66^{* * *}$ & $174.07^{* * *}$ & $164.75^{* * *}$ & $193.60^{* * *}$ & 191.62 \\
\hline direct ties & & & $.067^{* *}(.025)$ & & & $.069^{* *}(.025)$ & $.066(.025)$ \\
\hline $\begin{array}{l}\text { Similarity } \\
\text { Relation }\end{array}$ & $-.135^{*}(.054)$ & $.286^{* *}(.096)$ & $-.138^{* *}(.054)$ & $-.067(.053)$ & $.285^{* *}(.096)$ & $-.075(.053)$ & \\
\hline $\begin{array}{l}\text { indirect } \\
\text { ties }\end{array}$ & $-.074^{*}(.031)$ & $.703^{* * *}(.066)$ & $-.073^{*}(.031)$ & $-.078^{*}(.031)$ & $.686^{* * *}(.065)$ & $-.077^{*}(.031)$ & $-.078(.031)$ \\
\hline $\begin{array}{l}\text { knowledge } \\
\text { width }\end{array}$ & $.417^{* * *}(.070)$ & $-.084(.104)$ & $.419^{* * *}(.070)$ & $.396^{* * *}(.069)$ & $-.078(.106)$ & $.398^{* * *}(.069)$ & $.387(.069)$ \\
\hline $\begin{array}{l}\text { knowledge } \\
\text { depth }\end{array}$ & $.266^{* * *}(.036)$ & $-.026(.081)$ & $.270^{* * *}(.035)$ & $.266^{* * *}(.036)$ & $-.039(.080)$ & $.270^{* * *}(.035)$ & $.270(.035)$ \\
\hline $\begin{array}{l}\text { R\&D } \\
\text { strength }\end{array}$ & $.196^{+}(.101)$ & $-.025(.127)$ & $.190^{+}(.100)$ & $.175^{+}(.100)$ & $.021(.126)$ & $.171^{+}(.100)$ & $.162(.098)$ \\
\hline $\begin{array}{l}\text { company } \\
\text { size }\end{array}$ & $-.031(.101)$ & $.231(.145)$ & $-.024(.100)$ & $-.010(.100)$ & $.210(.146)$ & $-.004(.099)$ & $-.005(.099)$ \\
\hline Year-2006 & $.083(.058)$ & $-.140(.123)$ & $.074(.057)$ & $.089(.059)$ & $-.158(.123)$ & $.081(.058)$ & $.081(.058)$ \\
\hline Year-2007 & $-.038(.060)$ & $-.204(.135)$ & $-.039(.059)$ & $-.027(.061)$ & $-.227^{+}(.135)$ & $-.027(.059)$ & $-.022(.059)$ \\
\hline Year-2008 & $-.138^{*}(.070)$ & $-.180(.158)$ & $-.125^{+}(.069)$ & $-.128^{+}(.070)$ & $-.219(.157)$ & $-.116^{+}(.069)$ & $-.112(.069)$ \\
\hline Year-2009 & $-.529^{* * *}(.076)$ & $-.128(.171)$ & $-.512^{* * *}(.075)$ & $-.517^{* * *}(.076)$ & $-.214(.172)$ & $-.498^{* * *}(.076)$ & $-.500(.076)$ \\
\hline Constant & $1.753^{* * *}(.095)$ & $-.164(.142)$ & $1.765^{* * *}(.095)$ & $1.736^{* * *}(.096)$ & $-.143(.141)$ & $1.748^{* * *}(.095)$ & $1.744(.095)$ \\
\hline
\end{tabular}

Table 3 is results of Sobel test for Model 1 to 6 , that is suggested to judge the significant of $\mathrm{a} \times \mathrm{b} . \mathrm{z}=\frac{a b}{\sqrt{a^{2} S_{b}^{2}+b^{2} S_{a}^{2}}}$. c means the coefficient of $\mathrm{X}$ on $\mathrm{Y}$. c' means the coefficient of $\mathrm{X}$ on $\mathrm{Y}$ when $\mathrm{M}$ is controlled. a means the coefficient of $\mathrm{X}$ on $\mathrm{M}$. b means the coefficient of $\mathrm{M}$ on $\mathrm{Y}$. Sa and $\mathrm{Sb}$ means the standard error of $\mathrm{a}$ and $\mathrm{b}$. According to the method of Wen (2004), when technical similarity value is more than 0.3 , the technical similarity relation is negative to innovation performance, while the cooperative relation is a partly competitive mediator. According to the method of Zhao (2010), when technical similarity value is more than 0.5 , the technical similarity relation is negative to innovation performance, while the cooperative relation is a completely competitive mediator.

Table 3.The Sobel Test for Model 1 to 6

\begin{tabular}{|l|l|l|l|l|l|l|l|}
\hline Mediator: direct ties & c & $\mathbf{c}^{\prime}$ & $\mathbf{a}$ & Sa & b & Sb & Z \\
\hline Similarity Relation (>0.3) & $-.135^{*}$ & $-138^{* *}$ & $.286^{* *}$ & .096 & $.067^{* *}$ & .025 & $1.986^{*}$ \\
\hline Similarity Relation (>0.5) & -.067 & -.075 & $.285^{* *}$ & .096 & $.069^{* *}$ & .025 & $2.005^{*}$ \\
\hline
\end{tabular}

\section{Conclusion and Discussion}


We know from the Figure 3 and Table 2 and 3 that, the technical similarity networks from the threshold 0.3 to the threshold 0.5 can reflect the competition situation in the industry, that have negative effects on innovation performance, and the direct ties are partly or completely mediator. When the threshold of technical similarity network is less than 0.1 and great than 0.7 , the technical similarity relations have no effects on innovation performance, and the direct ties are not mediator. We know from the Figure 3 and Table 1 that, the technical similarity network is very density at threshold 0.1. The technical similarity relations cannot reflect the competition situation in the industry. But the technical similarity network is very discrete at threshold 0.7 . The technical similarity relations of many companies are zero because they have low technical similarity with others in the industry. The degree distribution of nodes in those two networks is not the normal distribution. It might be the reason that the technical similarity relations at threshold 0.1 or 0.7 have no significant negative influence on the innovation performance or the direct ties.

The degree of competition between two enterprises could be analyzed from two aspects (Chen, 1996). One is market commonality based on multipoint competition theory. The other is resource similarity based on resource base theory. Enterprises in the same industry provide a homogeneous product or service. That means the market commonality. The production using the same raw materials and accessing to raw materials also using the same channels, means the resource similarity. The higher overlapping degree in segments of the market, the higher similarity degree of resources, and the degree of competition between the two enterprises is higher (Xu, Zhang \& Long, 2008). The 88 communicating and technical equipment manufacturing enterprises are in the same industry. They provide similar productions or services on the industrial chain, such as communication technology and equipment manufacturing, network technology and operations services, computer and peripheral equipment manufacturing, chip and integrated circuit manufacturing. Technological innovation is frequent, and products and services are fast replaced by new products and services. Patents have become important strategic resources for enterprises to survive and develop. Patents reserve competition among enterprises becomes more and more fierce. Knowledge base overlapping is common phenomenon in the industry. The technology similarity based on patents could measure resources similarity between enterprises to some extent. The technology similarity relations could measure the degree of competition among enterprises to some extent. Dividing the technical field according to the IPC class, enterprises having much more same IPC categories might have technology competition relations. The technical similarity is good to knowledge sharing and transfer, but could cause technical competition among enterprises which may be bad to innovation. In the technical similarity network formed at the middle level of technical similarity degree, the technical similarity relations have negative influence on the innovation performance, while cooperative direct ties could be mediator of it, reduce the negative influence a little and good to innovation.

\section{Acknowledgements}

Supported by Innovation Program of Shanghai Municipal Education Commission (14YS102), Shanghai 085 Project (Z085GSGL13078) and the Central Government Finance Project (YC-XK-13104).

\section{References}

[1] G. Ahuja and R. Katila, "Technological Acquisitions and The Innovation Performance of Acquiring Firms: A Longitudinal Study”, Strategic Management Journal, vol. 22, (2001), pp. 197-220. 
[2] R. M. Baron and D. A. Kenny, "The Moderator-Mediator Variable Distinction in Social Psychological Research: Conceptual, Strategic, and Statistical Considerations", Journal of Personality \& Social Psychology, vol. 51, (1986), pp. 1173-1182.

[3] H. Bresman, J. Birkinshaw and R. Nobel, "Knowledge Transfer in International Acquisitions", Journal of International Business Studies, vol. 30, (1999), pp. 439-462.

[4] M. J. Chen, "Competitor Analysis and Interfirm Rivalry. Towards a Theoretical Integration", Academy of Management Review, vol. 21, no. 1, (1996), pp. 100-134.

[5] O. Granstrand and S. Sjolander, "The Acquisition of Technology and Small Firms by Large Firms", Journal of Economic Behavior \& Organization, vol. 3, no. 12, (1990), pp. 367-386.

[6] J. Hausman, B. H. Hall and Z. Griliches, "Econometric Models for Count Data with an Application to the Patents R\&D Relationship", Econometrica, vol. 52, (1984), pp. 909-938.

[7] H. Rui, Y. Jianmei and Y. Canzhong, "Research on Logistics Industry Competitive Relationship Model Based on Complex Networks", Chinese Journal of Management, vol. 7, no. 3, (2010), pp. 406-411.

[8] H. Hanhui and P. Ancheng, "Systemic Study on Organizational Knowledge Transfer and Learning Capability", "Journal of Management Sciences In China, vol. 9, no. 3, (2006), pp. 81-87.

[9] B. R. Koka and J. E. Prescott, "Designing Alliance Networks. The Influence of Network Position, Environmental Change, and Strategy on Firm Performance", Strategic Management Journal, vol. 29, no. 6, (2008), pp. 639-661.

[10] R. Larsson, L. Bengtsson, K. Henriksson and J. Sparks, "The Interorganizational Learning Dilemma: Collective Knowledge Development in Strategic Alliances”, Organization Science, vol. 9, (1998), pp. 285-305.

[11] C. Lechner, K. Frankenberger and S. W. Floyd, "Task Contingencies in the Curvilinear Relationships between Intergroup Networks and Initiative Performance", Academy of Management Journal, vol. 53, no. 4, (2010), pp. 865-889.

[12] L. Yan and C. Hong, "The Relationship between Knowledge Base and Innovative Performance: A Test in China's Electrical \& Electronic Industry", Science Of Science And Management Of S. \& T., vol. 32, no. 10, (2011), pp. 64-69.

[13] D. J. Miller, "Technological Diversity, Related Diversification, and Firm Performance", Strategic Management Journal, vol. 27, no. 7, (2006), pp. 601-619.

[14] Q. Xihong, Y. Yongfu and X. Wanli, "Enterprise Network Location, Absorptive Capacity and Innovation Performance --- An Interaction Effect Model", Management World, vol. 5, (2010), pp. 118129.

[15] R. C. Sampson, "R \& D Alliances and Firm Performance: The Impact of Technological Diversity and Alliance Organization on Innovation”, Academy of Management Journal, vol. 50, no. 2, (2007), pp. 364-386.

[16] W. Zhonglin and Z. Lei, "Testing And Application of The Mediating Effects", Acta Psychologica Sinica, vol. 36, no. 5, (2004), pp. 614-620.

[17] X. Xiyao, C. Hong and P. Yunlong, "Effect of Three Kinds of Proximity in International Patent Coapplication Network", Journal of Management Science, vol. 23, no. 5, (2010), pp. 43-52.

[18] X. Xiyao and C. Hong, "International Knowledge Transfer Network Structure Analysis -An Empirical Study Based on Patent Data", Studies in Science of Science, vol. 29, no. 1, (2011), pp. 97-105.

[19] X. Liang, Z. Zongyi and L. Yong, "Coopetition and Technical Innovation: Is Cooperation a Missing Link?", Studies in Science of Science, vol. 26, no. 5, (2008), pp. 1105-1113.

[20] Y. Yubing and P. Ancheng, "Study on The Relationship of Strong Tie Network, Overlapping Knowledge, Knowledge Transfer", Studies in Science of Science, vol. 27, no. 1, (2009), pp. 25-29.

[21] Z. Li and W. Fang, "Moderation and Mediation in Experimental Study", Journal of Management Science, vol. 24, no. 1, (2011), pp. 108-116.

[22] X. S. Zhao, J. G. Lynch and Q. M. Chen Jr., "Reconsidering Baron and Kenny: Myths and Truths about Mediation Analysis", Journal of Consumer Research, vol. 37, no. 2, (2010), pp. 197-206.

[23] Z. Xi, W. Xianwen, L. Zeyuan and H. Haiyan, "Network Measurement of Enterprises Technology Proximity Based on Patent Bibliometrics", Journal OF Intelligence, vol. 30, no. 1, (2011), pp. 90-93.

[24] M. Zollo, J. J. Reuer and H. Singh, "Interorganizational Routines and Performance in Strategic Alliances", Organization Science, vol. 11, no. 13, (2002), pp. 701-713.

\section{Authors}

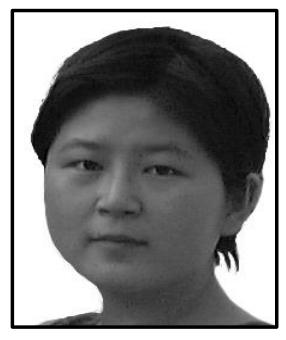

ZHANG Xiaoli, (1975), female, associate professor of Shanghai University of International Business and Economics, doctor of Shanghai University of Finance and Economics, research direction: the knowledge network and technology innovation management. 
International Journal of $u-$ and e- Service, Science and Technology

Vol.8, No. 8 (2015) 
International Journal of $u-$ and e- Service, Science and Technology Vol.8, No. 8 (2015) 